\title{
Design and Analysis of a Microstrip Patch Antenna for TV White Space Data Applications
}

\author{
Roy Francis Navea ${ }^{1}$, Emmanuel Trinidad ${ }^{2}$ \\ ${ }^{1}$ De La Salle University, Philippines, roy.navea@ dlsu.edu.ph \\ ${ }^{2}$ De La Salle University, Philippines, emmanuel_trinidad@dlsu.edu.ph
}

\begin{abstract}
The increasing number of smart and wireless devices demands for a more flexible allocation in the higher frequency spectrum. Dynamic spectrum access is one of the major candidates to solve the problem of spectrum scarcity. TV white spaces (TVWS) provide a means to opportunistically use the underutilized TV frequency bands in consideration with the gradual switching of the traditional TV broadcast to digital broadcasting. With smart devices in mini, micro, or nano circuit packaging, one of the major challenges is in the design of compact transceiver antennas suitable for mobile devices that operates in the Ultra High Frequency (UHF) band. This paper provides a brief overview of TVWS and a proposed microstrip patch antenna design. The geometric measurements and the antenna parameters were designed and simulated in MATLAB. Results show a resonant performance at the $638 \mathrm{MHz}$ operating frequency and a high front-to-back power ratio in the radiation pattern. The radiation characteristics are almost omni-directional in the azimuth while directional in the elevation plane. There is a minimal radiation at the back hence, for thin and slim devices, this will suit the desired application
\end{abstract}

Key words : Cognitive radio, microstrip, television, white space

\section{INTRODUCTION}

Advancements in wireless communication require the utilization of more electromagnetic frequency bands in the higher spectrum to increase bandwidth capacity over a light-range communication channel. As new and innovative communication devices are invented and manufactured for a varied range of applications, the scarcity in frequency resources also increases. In order to address this, a technique known as Dynamic Spectrum Access (DSA) is being utilized that allows the access to frequency bands in an efficient and effective manner. Digital switchover or analog TV bands being switched to digital formats allow the usage of frequencies which are being freed because of the migration. This allows dynamic access of Very High Frequencies (VHF) to Ultra High Frequencies (UHF) that are previously allocated for analog TV broadcast. A survey of spectrum in [1], shows the UHF band has an average occupancy of $16.17 \%$ in the Philippines. Cognitive radio allows the use of these frequencies to effectively utilize them either in time or geographical constraints in the TV spectrum. These bands are well suited for long-distance communications with good penetration to obstacles in the wireless link [2]. However, these bands should be accessed in a secure manner protecting the incumbent user or the primary users from the interference caused by the secondary user. This becomes a challenge to design antennas that can scan the whole frequency band and select the frequency of operation to be used.

Antennas are essential components in communication systems and the size of antennas depends on the frequency of operation may it be wired or wireless in nature. The acceptance of TV whitespace usage should be low cost to promote the usage of such technology. The desired whitespace devices (WSD) are required to be more compact, and this limits the design of the antenna that should operate to scan the whole frequency band of the TV spectrum to allow spectrum access. WSD access can be through geolocation database, spectrum sensing, or the utilization of both techniques. Microstrip patch antennas (MPA) are one of the candidates for this application. MPA's are easy to fabricate, low cost, and simple to analyze. Also, some advantages are the properties of patch antennas to be lightweight, low profile, and easy to fabricate. However, some disadvantages are noted which includes low radiating efficiency, poor polarization purity and scan performance, narrow frequency bandwidth, and must be operated at low power levels. These antennas are commonly patched in a ground substrate with specific relative permittivity. [3].

The microstrip patch antenna has been first proposed by Deschamps [4]. Literature shows that the usage of this type of antenna in different applications, combined with the advantages like low cost and ease of fabrication, which results to easier calculation, simulation, and experimentation. 
Roy Francis Navea et al., International Journal of Advanced Trends in Computer Science and Engineering, 10(3), May - June 2021, 1771 - 1775

Furthermore, the geometrical configurations antenna that ranges from rectangular, circular, and triangular shapes can be easily modified and can tune to the parameters needed which includes bandwidth and operating frequency [5]. In [6], a review of microstrip antenna designs for TVWS applications shows three wideband antennas wherein the shorted printed monopole antenna provides the highest gain of $2 \mathrm{~dB}$ to $4 \mathrm{~dB}$ with dimensions of $160 \mathrm{~mm} \times 170 \mathrm{~mm}$ [7]. A $59 \mathrm{~mm} \times 115 \mathrm{~mm}$ antenna was designed in [8] with a half bow-tie antenna printed with slots that provide a $50 \%$ total radiation efficiency at $470 \mathrm{MHz}$ to $860 \mathrm{MHz}$. The compact dimension and antenna design show a suitable use for portable devices for cognitive radio. Adding a meander line structure in the patch was implemented in [9] with a dimension of $46 \mathrm{~mm} \times 46 \mathrm{~mm}$ in a rectangular structure. Furthermore, the addition of the meander line is incorporated in the triangular patch in [10] with holes in the structure achieves a wideband performance with the dimension 120 $\mathrm{mm} \times 118 \mathrm{~mm}$. A folded printed monopole was implemented in [11] with the addition of a meander structure that aims to aid the mobile band in $706 \mathrm{MHz}$ to $940 \mathrm{MHz}$. Furthermore, a Multiple Input Multiple Output (MIMO) system is also implemented in [12] with two planar monopole antenna elements in a rectangular structure. This shows that the use of printed antennas and microstrip patches can easily be modified depending on the desired utilization in the UHF TVWS bands. In this paper, a design of a wideband antenna is proposed and simulated using MATLAB.

\section{ANTENNA DIMENSIONS}

Antenna dimension calculations are important considerations to achieve optimized design suited at the desired frequency of operation. In this paper, the transmission-line method was used as in [13]. The selected frequency of operation $\left(f_{o}\right)$ is for the TVWS device centered at $638 \mathrm{MHz}$. In addition, this frequency is in the UHF band that is close to the vacant frequency of $700 \mathrm{MHz}$ in the Philippine setting. The FR4 substrate was selected as a dielectric material between the patch and the ground plane with a dielectric constant $\left(\epsilon_{r}\right)$ of 4.4. The width (W) of the radiating patch is calculated using (1) where $c_{o}$ is the free space velocity of light.

$$
W=\frac{c_{o}}{2 f_{o}} \sqrt{\frac{2}{1+\epsilon_{r}}}
$$

After determining the width of the patch, the effective dielectric constant $\left(\epsilon_{\text {reff }}\right)$ can be computed due to the dispersion in air of the fringing field. The effective dielectric constant can be mathematically computed using (2) given the chosen height $(h)$ of the substrate.

$$
\epsilon_{r e f f}=\frac{\epsilon+1}{2}+\frac{\epsilon_{r}-1}{2}\left[1+12 \frac{h}{W}\right]^{-0.5}
$$

The length extension $(\Delta L)$ is computed as well to account for the fringing effects which make the radiating patch electrically long. Furthermore, the effective length can then be computed using (3) and (4).

$$
\begin{gathered}
\Delta L=0.412 h \frac{\left(\epsilon_{\text {reff }}+0.3\right)\left(\frac{W}{h}+0.264\right)}{\left(\epsilon_{\text {reff }}+0.258\right)\left(\frac{W}{h}+0.8\right)} \\
L_{e f f}=\frac{c_{o}}{2 f_{o} \sqrt{\epsilon_{\text {reff }}}}
\end{gathered}
$$

The ground plane length $\left(L_{g}\right)$ and width $\left(W_{g}\right)$ are computed by adding 6 times the height of the substrate where $L_{g}=L_{\text {eff }}+6 h$ and $W_{g}=W+6 h$ are the ground length and width, respectively. A coaxial - probe feeding was used to improve an impedance matching of 50 impedance. The first calculation was used using the equations in [14]. However, iterative testing of the feed location was used to match the desired operating frequency. The initial dimensions of the antenna are presented in Table 1.

Table 1: Calculated Antenna Dimensions

\begin{tabular}{|l|c|}
\hline \multicolumn{1}{|c|}{ Dimension } & Measurement $(\mathbf{m m})$ \\
\hline Width $(W)$ & 143 \\
\hline Length $(L)$ & 112 \\
\hline Ground Width $(W g)$ & 158 \\
\hline Ground Length $(L g)$ & 127 \\
\hline Height $(h)$ & 2.54 \\
\hline
\end{tabular}

\section{IMPLEMENTATION AND OPTIMIZATION}

The simulation of the antenna was performed in MATLAB with the Antenna Toolbox ${ }^{\circledR}$. The calculated dimensions were used as inputs for the rectangular patch antenna. Due to the iterative process of finding the coaxial probe feeding location, the design function of MATLAB was used to attain resonance at the $638 \mathrm{MHz}$ band. Using the design function of the software, a new set of dimensions of the patch were obtained as shown in Table 2 and illustrated in Figure 1.

Table 2: Revised Antenna Dimension

\begin{tabular}{|l|c|}
\hline \multicolumn{1}{|c|}{ Dimension } & Measurement $(\mathbf{m m})$ \\
\hline Width $(W)$ & 140 \\
\hline Length $(L)$ & 109 \\
\hline Ground Width $(W g)$ & 224 \\
\hline Ground Length $(L g)$ & 224 \\
\hline Height $(h)$ & 2.2 \\
\hline
\end{tabular}

The feed location with an offset from the center of the ground plane is $22.9 \mathrm{~mm}$ along the $\mathrm{x}$-axis. This optimization of the feed location shows resonance at the $638 \mathrm{MHz}$ frequency. 



Figure 1: Patch Microstrip Antenna Element: MATLAB Simulation

\section{RESULTS AND ANALYSIS}

In this section, the performance parameters of the antenna are presented which includes the S11 parameter, radiation pattern, elevation and azimuth patterns. A - $6 \mathrm{~dB}$ centered at the desired operation of frequency is shown in Figure 2 while a radiation pattern with $6.47 \mathrm{dBi}$ at $f_{o}$ in Figure 3. The $\mathrm{S} 11$ parameter describes the relationship between the input and output between ports / terminals in an electrical system. In this case, the $S_{11}$ parameter describes the reflected power of say, radio 1, to deliver in say, antenna 1. In Figure 2, the - $6 \mathrm{~dB}$ marks at the targeted frequency band of $638 \mathrm{MHz}$ as required in the antenna design.

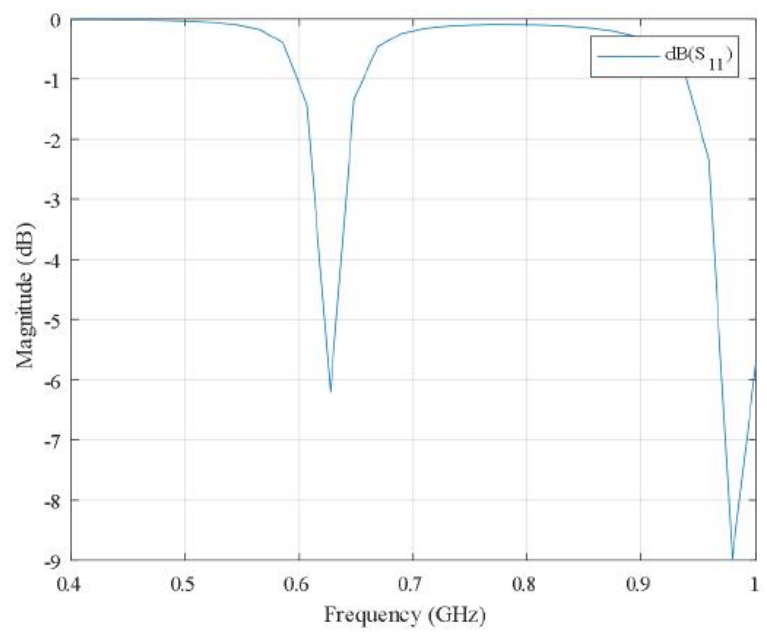

Figure 2: $\mathrm{S}_{11}$ Parameter, Magnitude vs. Frequency

In Figure 3, the radiation pattern at $638 \mathrm{MHz}$ provides a maximum gain of $6.47 \mathrm{dBi}$ and minimum of $-18.2 \mathrm{dBi}$. This is indicative of a significantly higher gain at the frontal lobe and low radiations at the back lobe making it a directional antenna [15]-[16].

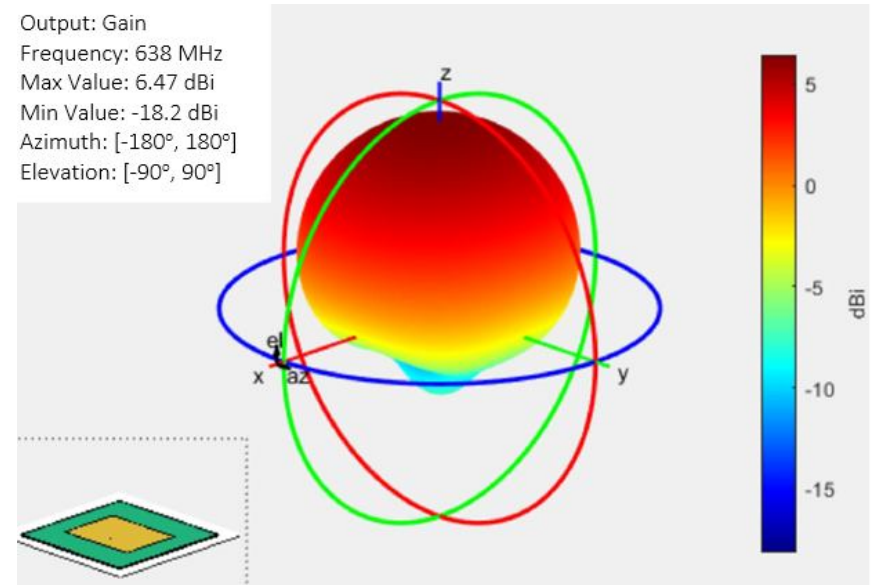

Figure 3: 3D Radiation Pattern at $638 \mathrm{MHz}$

The E-plane (azimuth) and H-plane (elevation) of the radiation pattern are respectively illustrated in Figure 4 and Figure 5. There are three back lobes in the elevation plane where the strongest is at $270^{\circ}$ behind the peak of the main lobe. The radiation characteristics are almost omni-directional in the azimuth while directional in the elevation plane. There is a minimal radiation at the back hence, for thin and slim devices, this will suit the desired application [16].

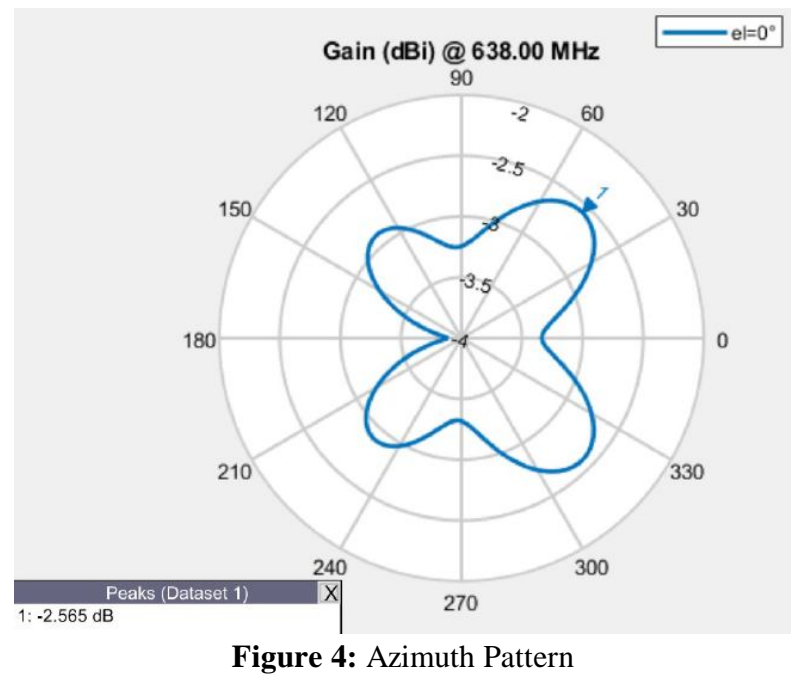




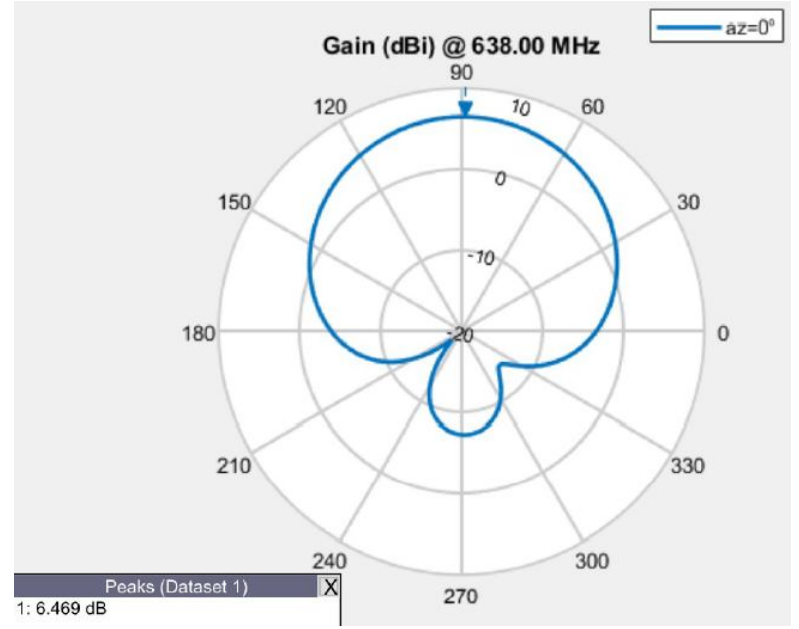

Figure 5: Elevation Pattern



Figure 6: Antenna Impedance

The impedance evaluation is graphed in Figure 6 showing a near zero reactance at the chosen frequency $638 \mathrm{MHz}$. This is an indication of resonance at the center frequency where the output signal is at its maximum and a minimum phase shift between the input and output signals is present [17].

\section{CONCLUSION}

A rectangular microstrip patch antenna is designed and evaluated at the targeted center frequency of $638 \mathrm{MHz}$ in the UHF band for TVWS application. The antenna shows resonance at the $638 \mathrm{MHz}$ with the dimension calculated and the coaxial fed point is also determined. The results and dimensions show the antenna to be a good candidate for fixed TVWS CPE modules, especially in rural areas.

For further optimization, the antenna can be optimized using algorithms and provide a larger bandwidth of the TVWS spectrum. The use of different geometries, fractal design, and defected ground structure are considered for future work for bandwidth improvement. With the modern advancements in material science, antennas can be fabricated in flexible designs [18] that would suit a variety of application not just in TV sets but also in mobile devices that can utilize the TV white space band.

\section{REFERENCES}

1. A. L. C. Pintor, M. R. S. To, J. S. Salenga, G. M. Geslani, D. P. Agpawa, and M. K. Cabatuan. Spectrum survey of VHF and UHF bands in the Philippines, in IEEE TENCON 2012, IEEE Region 10 Conference, 2012, pp. $1-6$.

2. S. W. Oh, Y. Ma, M.-H. Tao, and E. Peh, TV white space: The first step towards better utilization of frequency spectrum. John Wiley \& Sons, 2016.

3. C. A. Balanis, Antenna theory: analysis and design. John wiley \& sons, 2016.

4. G. A. Deschamps, Microstrip microwave antennas. Proceedings of the Third Symposium on the USAF Antenna Research and Development Program, Oct. 1953, pp. 18-22.

5. R. Kiruthika and T. Shanmuganantham, Comparison of different shapes in microstrip patch antenna for Xband applications, in International Conference on Emerging Technological Trends (ICETT). IEEE, 2016, pp. 1-6.

6. C. K. Vithanawasam, Y. L. Then, and H. T. Su, A review of microstrip antenna designs for TV white space applications, Indonesian Journal of Electrical Engineering and Computer Science, vol. 19, no. 2, pp. 855-863, 2020.

7. M. John and M. J. Ammann, A compact shorted printed monopole antenna for TV white space trials, in 7th European Conference on Antennas and Propagation (EuCAP), 2013, pp. 3713-3715.

8. J. Bauer and M. Sch"uhler, Compact wideband antenna for TV White Spaces," in the 8th European Conference on Antennas and Propagation (EuCAP 2014), 2014, pp. 2894-2896.

9. S. Bhole, A. Rathod, S. Doddipalli, S. Kannaiyan, and A. Kothari, A Compact Planar Antenna with Meander lines for TV White Space Applications, in 2018 IEEE International Students' Conference on Electrical, Electronics and Computer Science (SCEECS), 2018, pp. $1-4$.

10. I. S. Darwhekar, P. D. Peshwe, K. Surender, and A. G. Kothari, Wideband Triangular Patch Antenna for Cognitive Radio in TV White Space, in 2019 2nd International Conference on Innovations in Electronics, Signal Processing and Communication (IESC), 2019, pp. 115-118.

11. A. Loutridis, M. John, and M. Ammann, Printed folded meander line dual-band monopole for TV White space and GSM, in the 8th European Conference on Antennas and Propagation (EuCAP 2014), 2014, pp. 2848-2852.

12. A. Kakkar, N. Malay, and M. Tripathy, A novel two element mimo antenna for tv white space 
applications, in 2018 8th International Conference on Cloud Computing, Data Science Engineering (Confluence), 2018, pp. 320-323.

13. N. Ida, R. Ciocan, Use of Transmission Line Methods for Antenna Analysis and Wave Propagation. IEEE Transactions on Magnetics, 40(2):651-654

14. V. Hanumante, P. Bhattacharjee, S. Roy, P. Chakraborty, and S. Maity, Performance analysis of rectangular patch antenna for different substrate heights, International Journal of Innovative Research in Electrical, Electronics, Instrumentation and Control Engineering, vol. 2, no. 1, pp. 515-518, 2014

15. D.L.N. Fauzi, T. Hariyadi. Design of a Directional Microstrip Antenna at UHF-Band for Passive Radar Application, IOP Conf. Series. Materials Science and Engineering, vol. 384, 2018

16. V. Ubale, O.S.Lamba. Design of Multiband Printed Flexible antenna for Body Wearable Applications, International Journal of Advanced Trends in Computer Science and Engineering, vol. 9, no. 4, 2020

17. S. Saravani, S.M. Norzeli, N.M. Din, S. Deros, AA. Almisreb. Antenna Miniaturization of RF Energy Harvesting System for IoT Applications, International Journal of Advanced Trends in Computer Science and Engineering, vol. 9, no. 5, 2020

18. M. Pandimadevi, R. Tamilselvi, M.P. Beham. Design Issues of Flexible Antenna - A Review, International Journal of Advanced Trends in Computer Science and Engineering, vol. 8, no. 4, 2019 